\title{
Chromosomes in sexual populations of Notostracan and Con- chostracan taxa (Crustacea, Branchiopoda)
}

\author{
Marescalchi Ombretta ${ }^{1 *}$, Michele Cesari $^{1}$, Erich Eder $^{2}$, Franca Scanabissi $^{1}$ and Bar- \\ BARA MANTOVANi ${ }^{1}$ \\ ${ }^{1}$ Dipartimento di Biologia Evoluzionistica Sperimentale, Via Selmi 3, 40126, Bologna, Italia. \\ ${ }^{2}$ Institut für Zoologie der Universität Wien, Althanstrasse 14, A-1090, Wien, Österreich
}

\begin{abstract}
Branchiopods reproductive mechanisms range from gonochorism to unisexuality, passing through androdioecy. In order to contribute to still lacking or controversial basic knowledges, we analyzed the karyotype of the main Italian taxa: the Notostracan living fossils Triops cancriformis (parthenogenetic) and Lepidurus apus lubbocki (bisexual), and the Conchostracan Eoleptestheria ticinensis (bisexual). Also one male obtained from a supposedly hermaphroditic Austrian population of T. cancriformis was checked. In T. cancriformis a diploid number of 12 chromosomes is observed in both females and male; this is in line with previous results on other Italian populations, but contrasts with observations on European samples. The richness of normal meiotic pictures indicates that the male specimen is able to produce sperms. L. apus lubbocki shows a diploid number of 10 chromosomes; in male specimens the mispairings during meiosis I could explain the haploid number of 6 chromosomes obtained from diakinetic plates in Palestinian samples of the same subspecies found in literature. Irregular meiotic divisions also highlight the ultrastructurally observed abortive spermatogenesis. Finally, in the presently analyzed population of E. ticinensis, the adult females show 10 chromosomes as diploid number, while males present 10 or 11 elements; in the nauplii, chromosome numbers range from 8 to 12 , differing among unrelated individuals, between nauplii produced by the same female and even within the same nauplius. B elements are taken into account.
\end{abstract}

Key words: B-chromosomes; Eoleptestheria ticinensis; Karyology; Lepidurus apus lubbocki; Sex determination; Triops cancriformis.

\section{INTRODUCTION}

Notostraca and Conchostraca are Crustacean Branchiopods sharing a world-wide distribution, possibly related to their ancient origin. Conchostraca are reported from Devonian and Carboniferous periods and the two Notostracan genera, Triops Schrank 1803 and Lepidurus Leach 1816, have undergone nearly 200 Myr of morphological stasis. In spite of their "unusual morphological conservatism" (FISHER 1990), Notostraca and also Conchostraca show an extensive variation in their reproductive biology with an array of highly diversified reproductive modes that adds many problems to their taxonomy. In particular, reproductive strategies of even a single taxon may range from gonochorism (sex ratio varying in different populations from equality to a female or a male bias) to self fertilizing hermaphroditism and par-

* Corresponding author: phone +39 0512094172; fax +39 0512094286; e-mail: ombretta.marescalchi@unibo.it. thenogenesis; further, Triops newberryi (Packard) (Notostraca) and Eulimnadia texana Packard (Conchostraca) (Sassaman 1991, 1995; SAssaMAN et al. 1997; WeEKs et al. 2000) are known as androdioecious animal systems (populations embody males in low frequencies and self-compatible hermaphrodites).

Notostracan and Conchostracan have not been the subject of extensive cytogenetic research mainly because they have small chromosomes which are difficult to analyze carefully; karyological analyses have so far been very few or incomplete and have often led to contrasting results.

T. cancriformis Bosc 1801 has a very wide range, being distributed from North Africa and Europe to Japan. Its reproductive mode is extremely complex and still not fully understood: usually its populations are described as normally bisexual in the Southern regions of its range and hermaphroditic in the Northern ones (LonGHURST 1955; BRTEK and ThIÉRY 1995). ZAFFAgNinI and TRENTINI (1980), on the basis of cytological observations, reported a hermaphroditic 
condition of North Italian populations, recent electron microscopic analyses evidenced never testicular lobes (SCANabissi and Mondini 2002a), therefore these populations appear as true thelytokous parthenogens. Furthermore, ENGELMANN et al. $(1996,1997)$ provide evidence for a parthenogenetic and/or bisexual reproduction mode in a supposedly hermaphroditic German population. Karyological analyses too have given highly contrasting results: Moore (1893) described a single chromosome, LONGHURST (1955a) reported a diploid number of 8 chromosomes in ovotestes of European samples, while TRENTINI (1976) evidenced 12 chromosomes as diploid number on Italian females.

The Italian and Eastern Mediterranean populations of L. apus lubbocki Brauer 1873 have been described as being bisexual (Longhurst 1955a; b). The unique karyological datum on aceto-orcein squashes gave diakinesis stages with a haploid number of 6 in males (GoLDSCHMIDT 1953).

The Conchostracan taxon Eoleptestheria ticinensis Balsamo-Crivelli 1859 is bisexual, with normally developed females and males. Karyological data on an Italian population in Pavia indicated a diploid number of 10 in females and males (Tinti et al. 1994).

With the aim to contribute to a better knowledge of these peculiar animal systems, we analyzed cytologically Italian samples of $T$. cancriformis, L. apus lubbocki (Notostraca), and E. ticinensis (Conchostraca).

\section{MATERIALS AND METHODS}

Pertinent information on analyzed taxa is given in Table 1, together with a survey on litera- ture data. A male specimen from a supposedly hermaphroditic Austrian population and several Italian females of $T$. cancriformis were investigated for this study. Furthermore, at least two males, two females and several nauplii have been cytologically analyzed for $L$. apus lubbocki and $E$. ticinensis.

To obtain a larger number of metaphases and sharper centromere localization, samples were immersed in a $0.05 \%$ solution of colchicine for $3 \mathrm{~h}$ before dissection. Adult gonads or whole nauplii were then treated with a hypotonic solution of $1 \%$ $\mathrm{Na}$-citrate for $20 \mathrm{~min}$, fixed in 3:1 methanol-acetic acid for $30 \mathrm{~min}$ and dissociated on a clean slide with $60 \%$ acetic acid. Slides were stained with $3 \%$ Giemsa solution in phosphate buffer at $\mathrm{pH} 7$ for $20 \mathrm{~min}$. A representative number of metaphases (30-50) of each specimen were analyzed for both T. cancriformis and L. apus lubbocki; in E. ticinensis the best material for the observation of metaphase plates proved to be the nauplii, in adult animals it was possible to observe only 4-6 metaphases each.

\section{RESULTS}

The very small size of chromosomes $(0,5-1,5$ $\mu \mathrm{m})$ prevents their morphological characterization, so that no arrangement by size and shape can be obtained.

Triops cancriformis - A diploid number of 12 chromosomes is observed in both female and male mitotic metaphases (Fig 1a, b); in some male plates the smallest element bears secondary constrictions. The co-occurrence of regular and ir-

Table 1 - Collecting sites and diploid chromosome numbers of presently analyzed specimens in comparison with literature data.

\begin{tabular}{|c|c|c|c|c|}
\hline Species & Collecting site & $2 n$ & $\operatorname{sex}$ & references \\
\hline Triops cancriformis & $\begin{array}{c}\text { Wien (Austria) } \\
\text { Grosseto (Italy) } \\
\text { European } \\
\text { Pavia (Italy) }\end{array}$ & $\begin{array}{c}12 \\
12 \\
8 \\
12\end{array}$ & $\begin{array}{c}\text { male } \\
\text { females } \\
\text { hermaphrodite } \\
\text { females, nauplii }\end{array}$ & $\begin{array}{l}\text { present study } \\
\text { present study } \\
\text { Longhurst, } 1955 \\
\text { Trentini, } 1976\end{array}$ \\
\hline Lepidurus apus lubbocki & $\begin{array}{c}\text { C. Porziano (Italy) } \\
\text { Palestine }\end{array}$ & $\begin{array}{l}10 \\
12\end{array}$ & $\begin{array}{c}\text { males, females, nauplii } \\
\text { male }\end{array}$ & $\begin{array}{c}\text { present study } \\
\text { Goldschmidt, } 1953\end{array}$ \\
\hline Eoleptestheria ticinensis & Ferrara (Italy) & $\begin{array}{c}10,11 \\
10 \\
10 \\
8 \\
12 \\
10,12 \\
8,10 \\
9,11,12 \\
10\end{array}$ & $\begin{array}{c}\text { males } \\
\text { females } \\
\text { nauplii } \\
\text { nauplius } \\
\text { nauplius } \\
\text { nauplius } \\
\text { nauplius } \\
\text { nauplii } \\
\text { males, females }\end{array}$ & $\begin{array}{l}\text { present study } \\
\text { present study } \\
\text { present study } \\
\text { present study } \\
\text { present study } \\
\text { present study } \\
\text { present study } \\
\text { present study } \\
\text { Tinti et al., } 1994\end{array}$ \\
\hline
\end{tabular}




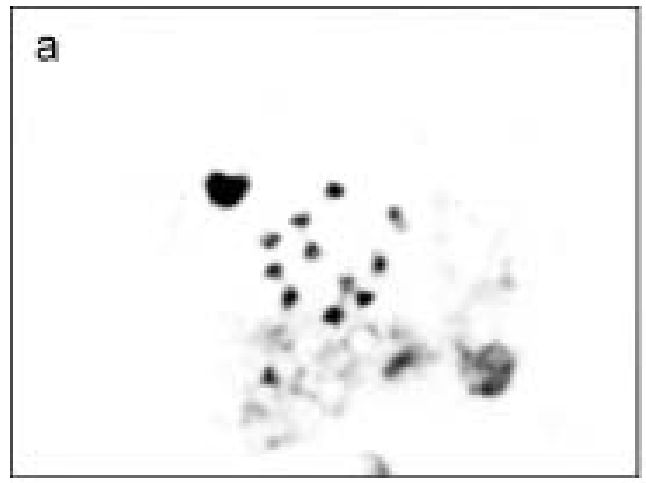

b
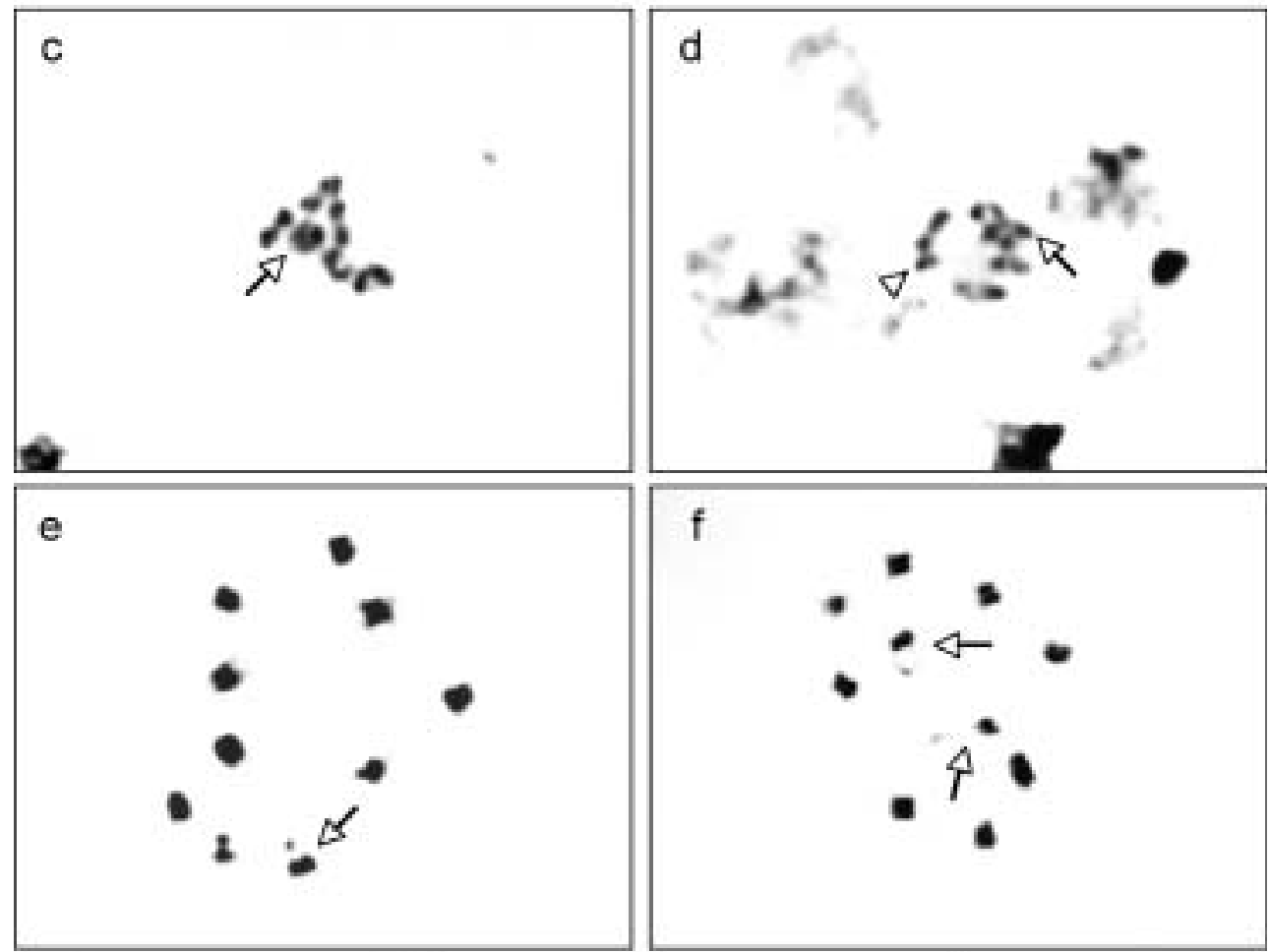

f
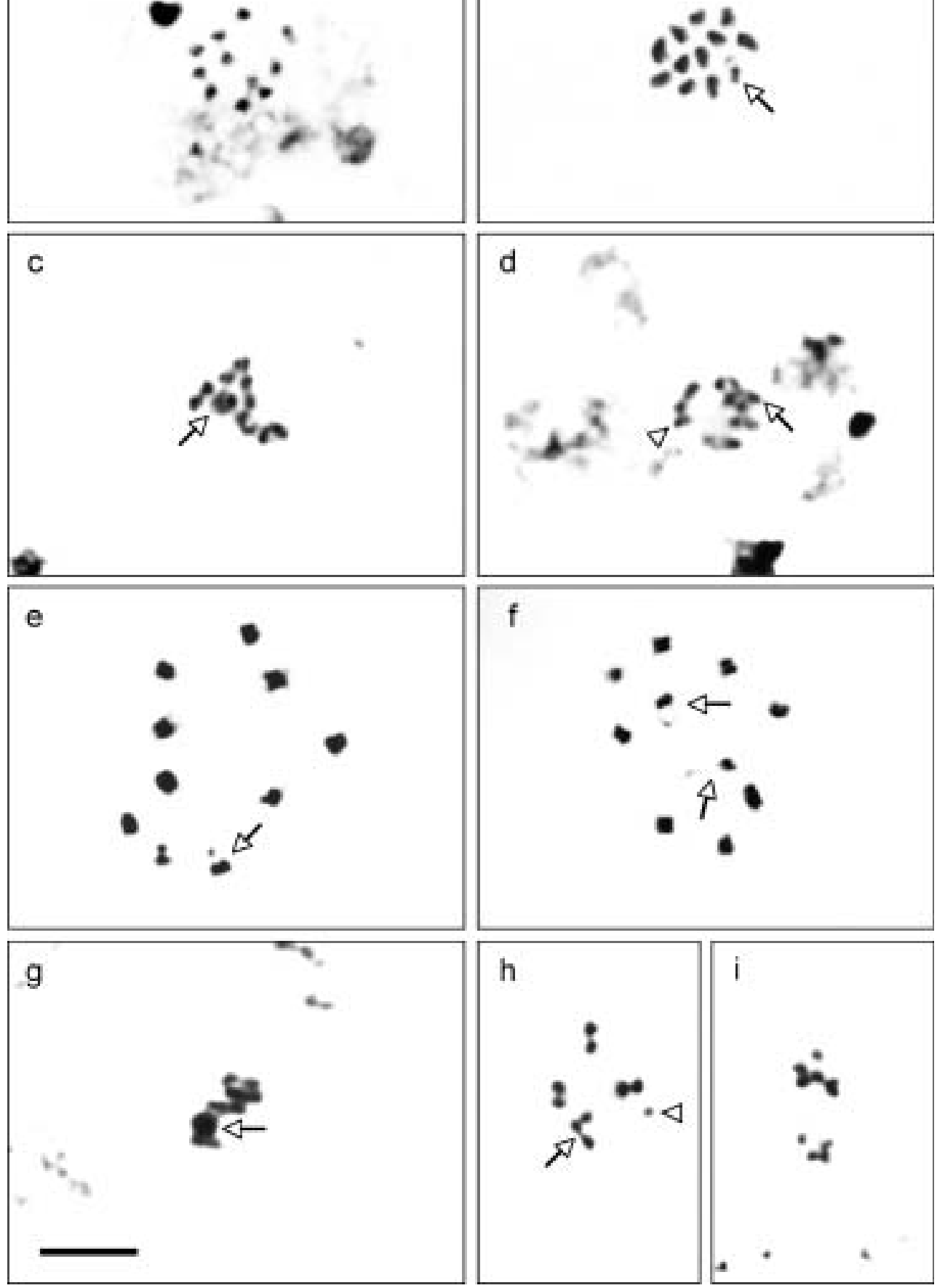

Fig. 1 - Triops cancriformis: female (a) and male (b) chromosome sets both showing 12 elements. A satellite is present on the smallest chromosome of the male complement (arrow). Seemingly regular male meiotic metaphase I with 6 bivalents one of which is ring-shaped (arrow) (c); irregular meiosis with a multivalent association (arrow) and an univalent (arrowhead) (d). Lepidurus apus lubbocki: female (e) and male (f) mitotic plates with 10 elements; arrows point the satellites present on the smallest chromosomes. Regular male meiotic metaphase I with 5 packed bivalents, arrow points the ring-shaped one ( $\mathbf{g}$ ); irregular meiosis I with one trivalent (arrow) and one unpaired chromosome (arrowhead) (h); unbalanced meiotic metaphases II with 4 and 6 elements respectively (i). All photomicrographs are Giemsa stained and at the same magnification; bar represents $5 \mu \mathrm{m}$. 
regular male meiotic metaphases I is evident: $60 \%$ of the plates are seemingly normal, with 6 bivalents as expected (Fig. 1c); the remaining $40 \%$ are irregular meiotic divisions with a trivalent association and one unpaired chromosome (Fig. 1d). The presence of one ring-shaped bivalent in all meiotic metaphases I suggests the existence of at least one pair of biarmed elements.

Lepidurus apus lubbocki - The diploid number in both female and male mitotic metaphases is 10 (Fig. 1e, f) and the same number has been scored in the analyzed nauplii. The smallest chromosome pair bears secondary constrictions, which are in heterozygous condition in the female set. Male meiotic metaphases I show 5 bivalents (Fig. 1g), thus confirming the observed diploid number. As in T. cancriformis, the ring-shape of one bivalent suggests the presence of at least two meta- or submetacentric elements. Half of male first meiotic divisions are irregular with both multivalent associations and unpaired chromosomes (Fig. 1h). These mispairings lead to anomalous metaphases II with an aneuploid number of chromosomes (Fig. 1i).

Eoleptestheria ticinensis - Counts clearly showed different diploid conditions. Interestingly, females always present 10 chromosomes (Fig. 2a), while in males 10 or 11 chromosomes can be detected (Fig. 2b,c). Males with 10 chromosomes show regular meiotic metaphases II with 5 elements (fig. 2 d). In males with 11 chromosomes, no meiotic plates were found. Nauplii show chromosome numbers ranging from 8 to 12 , also with different chromosome numbers cohexisting in the same individual (Table 1, Fig. 2e-h). In several mitotic metaphases ( $42 \%$ ) of both nauplii and adult animals, two chromosomes appear separate from the others (Fig. 2f).

In all examined species no heteromorphic chromosome pairs that could be clearly interpreted as sex chromosomes have been observed.

\section{DISCUSSION}

Present analyses confirm the difficulties that previous researchers have generally encountered in karyological studies of these branchiopods, owing to the very small size of chromosomes.

Our data on $T$. cancriformis females from Grosseto agree with the results of TrentinI (1976) on a population collected in Pavia; it is to be noted though that Italian data have been obtained on populations constituted only by females, in whose gonads no testicular lobes have ever been recorded. For the first time, also an Austrian male specimen - from a supposedly hermaphroditic population - has been analyzed: its diploid number is in agreement with that observed in Italian females and not with those of LONGHURST (1955a) on a rather vaguely defined "European" hermaphroditic sample. This diploid chromosome number is present also in T. longicaudatus (AkiтA 1971), where Longhurst found $2 n=8$. It should be pointed out that LONGHURST's counts were carried out on histological sections, whereas in both AkitA's and present analyses the squash method was used. The occurrence of numerical chromosomal differences in comparison to LONGHURST's data, strongly suggests to check also T. granarius and T. australiensis $(\mathrm{n}=4,8$ and $\mathrm{n}=5$ respectively; LONGHURST $1955 \mathrm{~b}$ ) in order to define if $2 \mathrm{n}=12$ is the prevalent chromosome number of the genus.

When comparing male and female karyotypes of $T$. cancriformis no hints to the presence of sex chromosomes are given. In Triops newberryi, sex appears to be controlled by a single locus, with a recessive allele coding for males and a dominant allele coding for hermaphrodites/females (SASSAMAN 1991; 1995; SASSAMAN and WeEks 1993). This sex determination model would be at present of difficult application in T. cancriformis, because males are either completely absent (Italian populations) or produced in low numbers (Austrian populations).

The presence of normal meiotic pictures, along with the anomalous ones, supported by ultrastructural investigation of the gonads (SCANABISSI et al. 2005), could suggest that the Austrian male is fertile and may have at least the physiological option to fertilize ova.

It has yet to be determined whether the low number of males in this supposedly hermaphroditic European population represents the relict of an androdioecious system or is indicative of an attempt towards this peculiar reproductive system. Ultrastructural analyses could highlight the role of males verifying the presence of testicular lobes in female specimens: this Austrian population could parallel the gonochoric German one characterized by the presence of few males and females failing to show histological signs of hermafroditism (ENGELMANN et al. 1997).

As far as L. a. lubbocki is concerned, our data on adults of both sexes and on nauplii indicate 10 chromosomes as diploid number, at variance with the only existing datum on the same subspecies from Palestine ( $\mathrm{n}=6$; Goldschmidt 1953; LongHURST 1955a; b). Differences with the diploid 

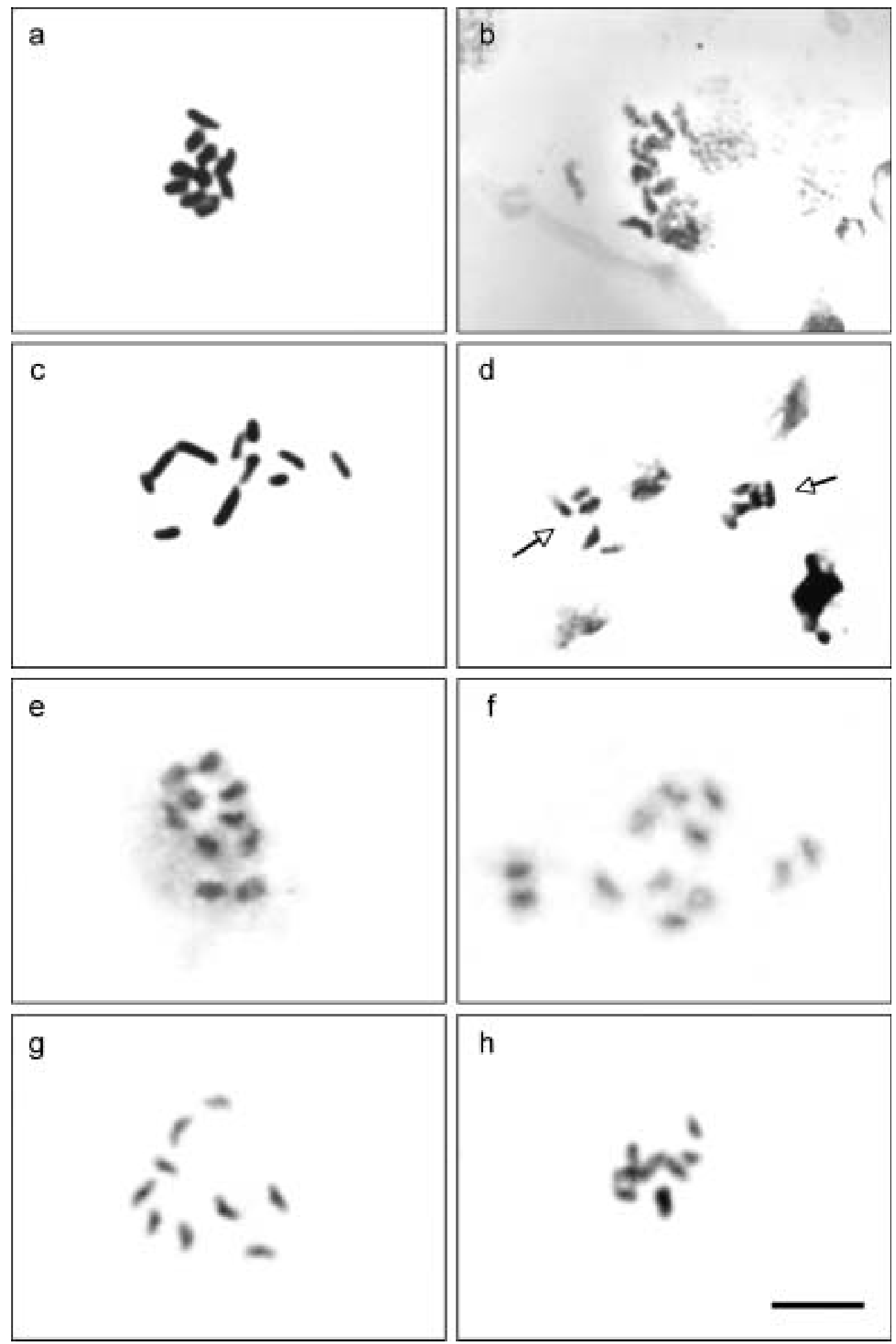

$\mathrm{h}$

Fig. 2 - Eoleptestheria ticinensis: female mitotic metaphase with 10 chromosomes (a); male mitotic plates showing 10 and 11 elements respectively $(\mathbf{b}, \mathbf{c})$; male meiotic metaphase II with 10 chromosomes: each group contains 5 elements (arrows) (d); mitotic plates from a same nauplius with 10 and 12 chromosomes respectively (e, f); mitotic metaphases of different nauplii showing 9 and 8 elements $(\mathbf{g}-\mathbf{h})$. All photomicrographs are Giemsa stained and at the same magnification; bar represents $5 \mu \mathrm{m}$. 
chromosome number emerging from GolDSCHMIDT's observations on male meiotic divisions could be explained taking into account meiosis I mispairings, which we observed in half of the analyzed metaphases.

A recent ultrastructural analysis on male specimens from the Italian population of Castel Porziano (Rome) - highlighting previous comparable observations on a Palestinian sample (WINGSTRAND 1978) - showed an abortive spermatogenesis, so that males are unable to produce functional sperms (SCANabissi and Mondini 2002a; b). This abortive gametogenesis could be correlated to the several mispairings observed, leading to aneuploid nuclei. Keeping also in mind that, in the Castel Porziano population, males outnumber females (data collection is in progress), the male role in L. apus lubbocki needs to be explained.

Finally, the presently analyzed population of E. ticinensis shows a peculiar situation: first of all, only the two adult females show a diploid number of 10 chromosomes, while males present 10 or 11 elements; secondly, nauplii present variable chromosome numbers among unrelated individuals, among nauplii born from the same female and even within the same nauplius; third, mitotic plates with two chromosomes laying apart from the rest are often observed; fourth, the analyzed field-collected population shows a significant male bias approaching a 3:1 male/female-ratio (unpublished).

It is to be noted that in recent years B-chromosomes (i.e. extra chromosomes with non-Mendelian inheritance) have been shown to be involved in male-biased sex-ratios, with a possible dosage effect, in both insects and the anostracan Branchipus schaefferi (CAMACHO et al. 2000; Beladjal et al. 2002). On the whole, the male bias observed in natural populations of E. ticinensis together with a variable diploid chromosome number could suggest the presence of supernumerary chromosomes. This will be checked by means of chromosomal analyses of laboratory reared couples and relative offspring.

As a concluding remark, present analyses point to a very complex karyotypic situation in Notostraca and Conchostraca and calls for further studies to elucidate their reproductive strategies and sex-determination mechanisms.

Acknowledgments - We wish to thank for their support in specimen collecting dr. S. Fralassi (Azienda S.Carlo, Principina a Mare, Grosseto), dr. N. Ranco of Ente Nazionale Risi (Codigoro, Ferrara), and the Tenuta Presidenziale di Castel Porziano (Rome). Last but not least, a special thank to our technician dr. Paola Nisticò and to David Levi for language revision.

This work was supported by M.U.R.S.T. 40\% funds.

\section{REFERENCES}

Akita M., 1971 - On the reproduction of Triops longicaudatus (LeConte) from Arizona. Zool Mag, 80: 242-250.

Beladial L., Vandekerckhove T.T.M., Muyssen B., Heyrman J., de Caesemaeker J. and Mertens J., 2002 - B-chromosomes and male-biased sex ratio with paternal inheritance in the fairy shrimp Branchipus schaefferi (Crustacea, Anostraca). Heredity, 88: 356-360.

Brtek J. and Thiéry A., 1995 - The geographic distribution of the European branchiopods (Anostraca, Notostraca, Spinicaudata, Levicaudata). Hydrobiologia, 298: 263-280.

Camacho J.P.M., Sharbel T.F. and Beukeboom L.W., 2000 - B-chromosome evolution. Philosophical Transaction of the Royal Society of London B, 355: 163-178.

Engelmann M., Hoheisel G., Hahn T., Joost W., Vieweg J. and Naumann W., 1996 - Population of Triops cancriformis (Bosc) (Crustacea, Notostraca) in Germany northerly $50^{\circ} \mathrm{N}$ are not clonal and at best facultatively hermaphroditic. Crustaceana, 69: 755-768.

Engelmann M., Hahn T. and Hoheisel G., 1997 Ultrastructural characterization of the gonads of Triops cancriformis (Crustacea, Notostraca) from populations containing both females and males: no evidence for bermaphroditic reproduction. Zoomorphology, 117: 175-180

FisHER D.C., 1990 - Rate of evolution in living fossils. In: D.E.G. Briggs and P.R. Krauther (Eds), "Paleobiology”, p. 152-159. Blackwell Scientific, London.

Goldschmidt E., 1953 - Chromosome number and sex mechanism in Euphyllopods. Experientia, 9: 6569.

Longhurst A.R., 1955a - The reproduction and cytology of the Notostraca (Crustacea, Phyllopoda). Proceedings of the Zoological Society of London, 125: 671-680.

Longhurst A.R., 1955b - A review of the Notostraca. Bullettin of the British Museum of Natural History D, 3: 1-57.

Moore E.S., 1893 - Some points in the origin of the reproductive elements in Apus and Branchipus. Quarterly Journal of Microscopical Science, 35: 259-284.

Sassaman C., 1991 - Sex ratio variation in female-biased populations of Notostracans. Hydrobiologia, 212: 169-179.

SASSAMAN C., 1995 - Sex determination and evolution of unisexuality in the Conchostraca. Hydrobiologia, 298: 45-65. 
Sassaman C. and Weeks S.C., 1993 - The genetic mechanism of sex determination in the conchostracan shrimp Eulimnadia texana. American Naturalist, 141: 314-328.

Sassaman C., Simovich M.A. and Fugate M., i 997 Reproductive isolation and genetic differentiation in North American species of Triops (Crustacea: Branchiopoda: Notostraca). Hydrobiologia, 359: 125 147.

Scanabissi F. and Mondini C., 2002a - A survey of the reproductive biology in Italian branchiopods. Part $A$. The female gonad of Limnadia lenticularis (Linnaeus, 1761) (Spinicaudata) and Lepidurus apus lubbocki Brauer, 1873 (Notostraca). Hydrobiologia, 486: 263-272.

Scanabissi F. and Mondini C., 2002b - A survey of the reproductive biology in Italian branchiopods. Part. B. The male gonad of Lepidurus apus lubbocki Brauer, 1873 (Notostraca). Hydrobiologia, 486: 273 278.

Scanabissi F., Eder E. and Cesari M., 2005 - Male occurrence in Austrian Triops cancriformis (Branchiopoda, Notostraca) populations and ultrastruc- tural observations of the male gonad. Invertebrate Biology, 124: 58-66.

Tinti F., Tommasini S. and Scanabissi F., 1994 Chromosome analysis of Eoleptestheria ticinensis and Leptestheria dahalacensis (Branchiopoda, Spinicaudata). Zoologischer Anzeiger, 232: 15-20.

Trentini M., 1976 - Karyologic observations on Triops cancriformis (Phyllopoda, Notostraca). Bollettino di Zoologia, 43: 321-322.

Weeks S.C., Crosser B.R., Bennett R., Gray M. and ZuCKER N., 2000 - Maintenance of androdioecy in the freshwater shrimp, Eulimnadia texana: estimates of inbreeding depression in two populations. Evolution, 54 (3): 878-887.

Wingstrand K.G., 1978 - Comparative spermatology of the Crustacea Entomostraca. 1. Subclass Branchiopoda. Biologiske Skrifter Danske Videnskabernes Selskabs, 22: 1-66.

Zaffagnini F. and Trentini M., 1980 - The distribution and reproduction of Triops cancriformis (Bosc) in Europe (Crustacea, Notostraca). Monitore Zoologico Italiano, 14: 1-8.

Received 20.7.2004; accepted 12.5.2005 